\title{
Genome-Wide Identification, Expression Profile and Evolution Analysis of Karyopherin $\beta$ Gene Family in Solanum tuberosum Group Phureja DM1-3 Reveals Its Roles in Abiotic Stresses
}

\author{
Ya Xu ${ }^{1,2}$, Lu Liu ${ }^{2}$, Pan Zhao ${ }^{2}$, Jing Tong ${ }^{3}$, Naiqin Zhong ${ }^{2,4}$, Hongji Zhang ${ }^{1, *}$ and Ning Liu ${ }^{2,3, *}$ \\ 1 College of Plant Protection, Yunnan Agricultural University, Kunming 650201, China; xuyapoppy@163.com \\ 2 State Key Laboratory of Plant Genomics, Institute of Microbiology, Chinese Academy of Sciences, \\ Beijing 100101, China; liulu183@mails.ucas.ac.cn (L.L.); zhaop@im.ac.cn (P.Z.); nqzhong@im.ac.cn (N.Z.) \\ 3 National Engineering Research Center for Vegetables, Beijing Vegetable Research Center, Beijing Academy of \\ Agricultural and Forestry Sciences, Beijing 100097, China; tongjing@nercv.org \\ 4 The Enterprise Key Laboratory of Advanced Technology for Potato Fertilizer and Pesticide, \\ Inner Mongolia Autonomous Region, Hulunbuir 021000, China \\ * Correspondence: liuning@im.ac.cn (N.L.); zhanghongji111@163.com (H.Z.)
}

Received: 3 December 2019; Accepted: 28 January 2020; Published: 31 January 2020

\begin{abstract}
In eukaryotic cells, nucleocytoplasmic trafficking of macromolecules is largely mediated by Karyopherin $\beta /$ Importin $(K P N \beta$ or $\operatorname{Imp} \beta$ ) nuclear transport factors, and they import and export cargo proteins or RNAs via the nuclear pores across the nuclear envelope, consequently effecting the cellular signal cascades in response to pathogen attack and environmental cues. Although achievements on understanding the roles of several KPN $\beta$ s have been obtained from model plant Arabidopsis thaliana, comprehensive analysis of potato $K P N \beta$ gene family is yet to be elucidated. In our genome-wide identifications, a total of 13 StKPN $\beta$ (Solanum tuberosum KPN $\beta$ ) genes were found in the genome of the doubled monoploid S. tuberosum Group Phureja DM1-3. Sequence alignment and conserved domain analysis suggested the presence of importin- $\beta$ N-terminal domain (IBN_N, PF08310) or Exporin1-like domain (XpoI, PF08389) at N-terminus and HEAT motif at the C-terminal portion in most StKPN $\beta$ s. Phylogenetic analysis indicated that members of StKPN $\beta$ could be classified into 16 subgroups in accordance with their homology to human KPN $\beta$ s, which was also supported by exon-intron structure, consensus motifs, and domain compositions. RNA-Seq analysis and quantitative real-time PCR experiments revealed that, except $S t K P N \beta 3 d$ and $S t K P N \beta 4$, almost all $S t K P N \beta$ s were ubiquitously expressed in all tissues analyzed, whereas transcriptional levels of several StKPN $\beta$ s were increased upon biotic/abiotic stress or phytohormone treatments, reflecting their potential roles in plant growth, development or stress responses. Furthermore, we demonstrated that silencing of StKPN $\beta 3 a$, a SA- and $\mathrm{H}_{2} \mathrm{O}_{2}$-inducible $K P N \beta$ genes led to increased susceptibility to environmental challenges, implying its crucial roles in plant adaption to abiotic stresses. Overall, our results provide molecular insights into $S t K P N \beta$ gene family, which will serve as a strong foundation for further functional characterization and will facilitate potato breeding programs.
\end{abstract}

Keywords: karyopherin; solanum tuberosum; abiotic stress; expression analysis

\section{Introduction}

Unlike the prokaryotic ancestors, the nucleus of eukaryotic cells is surrounded by double layers of lipid membranes, called the nuclear envelope (NE), which provides a controlled barrier between nucleoplasm and cytoplasm [1-3]. The selective transportation of macromolecules across NE provides 
the eukaryotic cell with essential and additional benefits in regulating exchange of genetic information in response to the changing environments [4-6]. The nucleocytoplasmic transport machinery is composed of a variety of nuclear transport factors: (1) Karyopherin/Importin $\alpha$ (KPN $\alpha)$, which recognize cargo protein with nuclear localization signal (NLS) or nuclear export signal (NES); (2) Karyopherin/Importin $\beta$ (KPN $\beta$ ), which binds to KNP $\alpha$ and mediates cargo import into or export out of the nucleus; (3) A small GTPase Ran, which binds to KPN $\beta$ and drive directional nucleocytoplasmic transport of cargo- $\alpha / \beta /$ Ran complex by the RanGTP-RanGDP gradient across the NE [6-11]. In addition to collaborate with $\mathrm{KPN} \alpha$ in nucleocytoplasmic transport, the KPN $\beta$ family of nuclear transport factors can mediate, by directly recognizing NLS/NES with cargos, most macromolecular transport across NE. Therefore, KPN $\beta$ s are thought to be critical regulators of a set of cellular processes such as signal transduction, gene expression, immune response, etc. [12,13].

$\mathrm{KPN} \beta$ is typically characterized with an importin- $\beta$ N-terminal domain (IBN_N, PF03810) or Exporin1-like domain (XpoI, PF08389) at the N-terminus, and a series of tandemly repeated HEAT (Huntingtin, elongation factor 3, protein phosphatase 2A and yeast PI3-kinase TOR1) motifs at the C-terminal portion $[13,14]$. Based on the evolutionary and transcriptional analysis, KPN $\beta$ family is divided into 15 subfamilies which are named according to human nomenclatures [15,16]. Previous experiments have demonstrated that at least 11 human $\mathrm{KPN} \beta \mathrm{s}$ and 10 yeast KPN $\beta$ s can regulate nucleocytoplasmic transport [13].

Members of KPN $\beta$ gene family were identified in many eukaryotic organisms from yeast, plant, to mammal. It has been reported that there are 14 members in yeast and over 20 in human genomes, and Arabidopsis genome encodes $18 \mathrm{KPN} \beta$ proteins, suggesting individual members of KPN $\beta$ gene family might have their unique features $[12,17,18]$. Current knowledge on plant KPN $\beta$ genes were mostly obtained from functional analysis of Arabidopsis importin mutants [15,19]. For example, AtKPNB1, member of KPN 11 subfamily, modulates abscisic acid (ABA) signaling and its loss-of-function mutant exhibits enhanced tolerance to dehydration stress due to the increase sensitivity of stomatal closure in response to ABA [20]. PAUSED, an ortholog of human LOS1/XPOT in Arabidopsis, is capable of rescuing the tRNA export defect of los1 in Saccharomyces cerevisiae Meyen ex E.C. Hansen, indicating that their functions are highly evolutionarily conserved [21,22]. However, their genomic distribution and biological functions in plant species other than Arabidopsis thaliana, to our knowledge, has been largely uninvestigated yet.

Potato (Solanum tuberosum), grown on all continents except Antarctica, is the world's third most important staple crop after rice and wheat in terms of food consumption [23-25]. Although most cultivated potatoes are heterozygous autotetraploid and possess the huge genome, wild diploid potatoes with relatively smaller genome become the ideal targets of potato genome sequencing, which could adequately simplify the genome complexity [26]. Furthermore, wild diploid potatoes are widely used as sources of resistance by potato breeders because they are important reserves of genetic and phenotypic variation to biotic and abiotic stresses [27]. The diploid S. tuberosum Group phureja DM, cultivated in South America, was chosen to produce a homozygous double-monoploid clone (S. tuberosum group Phureja DM1-3 516 R44) using classical tissue culture techniques [25]. The annotated genome of S. tuberosum Group phureja DM1-3, was released in 2011 [26], and afterwards draft genome sequence of Solanum commersonii, a tuber-bearing wild potato, was also available in 2015 [28-30]. The genomic information released facilitates the researches on potato functional genomics, and provides an opportunity to conduct genome-wide analysis of nucleocytoplasmic transporters in potato. Here, we performed a genome-wide, comprehensive analysis of $K P N \beta$ genes. In total, 13 KPN $\beta$ genes were identified, and further confirmed by sequencing. The physical and chemical characteristics, genomic structures, chromosomal locations, evolutionary relationship, expression profiles of potato $K P N \beta$ gene family were analyzed in detail. Finally, VIGS (Virus-Induced Gene Silencing) approach was employed to investigate the role of potato $K P N \beta 3 a$, demonstrating that $K P N \beta 3 a$ was associated with plant adaption to salt and oxidative stresses. This study provides the molecular information with 
respect to the $S t K P N \beta$ gene family, paving the way to the further functional characterization of potato $K P N \beta$ genes.

\section{Results}

\subsection{Genome-Wide Identification of KPN $\beta$ Genes from S. tuberosum}

To identify KPN $\beta$ genes in potato, protein sequences of functionally validated KPN $\beta$ s from S. cerevisiae, Homo sapiens Linnaeus and A. thaliana were used as the queries to perform BLASTP searches against the potato genome database in Phytozome as well as Potato Genomics Resource. After removing the non-representative splicing forms of same gene locus, $14 \mathrm{KPN} \beta$-like genes were obtained from the genome sequences of $S$. tuberosum phureja DM1-3. Further, the presence of the IBN_N (or XpoI) and Heat repeats domains in these KPN $\beta$-like proteins was scanned using the Conserved Domain Search (CD-search) with e-value $<10^{-10}$. One possible pseudogene (PGSC0003DMG400029568) was removed from our analysis because its expression could not be detected in all samples and conditions examined in subsequent expression analysis, although its protein sequence is identical to KPN $\beta 3 d$. Eventually, only 13 genes were identified as $S t K P N \beta$ genes (Table 1). According to the homologies against Arabidopsis and human KPN $\beta \mathrm{s}$, the nomenclature of these $S t K P N \beta$ genes was listed in Table 1. The predicted proteins encoded by $S t K P N \beta$ varied from 239 amino acids (StKPN $\beta 3$ c) to 1111 amino acids (StKPN $\beta 3 \mathrm{a}$ ), with corresponding molecular weights from $27.2 \mathrm{kDa}$ to $123.1 \mathrm{kDa}$. Of these putative StKPN $\beta$ proteins, the theoretical isoelectric points ranged from 4.22 (StPLANTKAP) to 6.10 (StKPN $\beta 3 \mathrm{~d}$ ), indicating that, as weakly acidic proteins, they could participate biochemical processes under disparate in vivo environments.

\subsection{Chromosomal Distribution and Duplication Events among StKPN $\beta$ Genes}

The physical map position of $S t K P N \beta$ genes on 12 potato chromosomes was established. The number of $S t K P N \beta$ s are unevenly distributed on the potato chromosomes (Figure 1). Chromosome 1 contains the largest number of $S t K P N \beta$ genes comprising six members, chromosome 3 and 9 each contain two members, whereas chromosome 6, 8 and 12 each contain a single StKPN $\beta$.

The number of $S t K P N \beta$ genes in potato genome is similar to its counterparts in yeast, human and Arabidopsis. Pairwise sequence comparison of StKPN $\beta$ proteins suggests that the homology broadly ranged from $4.58 \%$ (StXPO5 and StXPO2) to $91.71 \%$ (StKPN $\beta 1 \mathrm{~b}$ and StKPN $\beta 1 \mathrm{a}$ ). Strikingly, through the sequence similarity between StKPN $\beta$ s, members in two subclades comprising StKPN $\beta 1 \mathrm{a} / 1 \mathrm{~b} / 1 \mathrm{c}$ share high sequence identity (64.4-91.7\%), suggesting that these StKPN $\beta$ s in KPN $\beta 1$ subfamily are likely to be originated from gene duplications while they are positioned to different chromosomes. A similar event was also found in KPN $\beta 3$ subclade, which includes StKPN $\beta 3 \mathrm{a} / 3 \mathrm{~b} / 3 \mathrm{c} / 3 \mathrm{~d}$ with identity from $34.3 \%$ to $90.5 \%$. 
Table 1. List of putative StImp $\beta$ gene family members of S. tuberosum Group phureja.

\begin{tabular}{|c|c|c|c|c|c|c|c|c|c|}
\hline \multirow{2}{*}{ Gene Name ${ }^{a}$} & \multirow{2}{*}{ Locus ID $^{b}$} & \multirow{2}{*}{ Predicted Proteins } & \multicolumn{3}{|c|}{ Chromosomal Location $^{c}$} & \multirow{2}{*}{ Gene Models ${ }^{d}$} & \multicolumn{3}{|c|}{ Putative Proteins ${ }^{e}$} \\
\hline & & & Chr & Chr_start & Chr_end & & Length (aa) & $\mathrm{pI}$ & MW (kDa) \\
\hline StKPN $\beta 1 a$ & PGSC0003DMG400018525 & PGSC0003DMP400032281 & 3 & 45710853 & 45713572 & 1 & 871 & 4.61 & 96.40 \\
\hline StKPN $\beta 1 b$ & PGSC0003DMG400019597 & PGSC0003DMP400034029 & 6 & 38386746 & 38389457 & 1 & 868 & 4.59 & 96.00 \\
\hline StKPN $\beta$ 1c & PGSC0003DMG400026641 & PGSC0003DMP400046282 & 9 & 10350557 & 10353269 & 1 & 873 & 4.62 & 96.22 \\
\hline StKPN $\beta 3 a$ & PGSC0003DMG400015862 & PGSC0003DMP400027802 & 1 & 16901021 & 16911855 & 1 & 1111 & 4.74 & 123.08 \\
\hline StKPN $\beta 3 b$ & PGSC0003DMG401004281 & PGSC0003DMP400007618 & 12 & 61091176 & 61100591 & 1 & 1021 & 4.77 & 113.87 \\
\hline$S t K P N \beta 3 c$ & PGSC0003DMG400023766 & PGSC0003DMP400055376 & 1 & 1281756 & 1283167 & 1 & 239 & 4.73 & 27.15 \\
\hline$S t K P N \beta 3 d$ & PGSC0003DMG400013325 & PGSC0003DMP400051493 & 8 & 45306052 & 45311794 & 1 & 983 & 6.10 & 109.56 \\
\hline StKPN $\beta 4$ & PGSC0003DMG400032173 & PGSC0003DMP400041127 & 1 & 80738183 & 80745787 & 5 & 1049 & 4.87 & 115.27 \\
\hline StKAP120 & PGSC0003DMG401000117 & PGSC0003DMP400011095 & 9 & 9658233 & 9662484 & 1 & 307 & 5.28 & 33.77 \\
\hline StPLANTKAP & PGSC0003DMG400006259 & PGSC0003DMP400021286 & 1 & 34095216 & 34099108 & 1 & 438 & 4.22 & 49.23 \\
\hline StXOPT & PGSC0003DMG400012034 & PGSC0003DMP400039669 & 3 & 61569820 & 61577676 & 4 & 990 & 5.44 & 111.51 \\
\hline StXPO2 & PGSC0003DMG400022883 & PGSC0003DMP400000259 & 1 & 73593165 & 73596092 & 1 & 975 & 5.52 & 109.63 \\
\hline StXPO5 & PGSC0003DMG400022491 & PGSC0003DMP400038992 & 1 & 75806958 & 75808695 & 1 & 320 & 6.00 & 35.01 \\
\hline
\end{tabular}

${ }^{a}$ Name referred to systematic designation to members of KPN $\beta$ family in S. tuberosum according to the homology against Homo sapiens. ${ }^{\mathrm{b}}$ Gene accession number in PGSC database. ${ }^{c}$ Chromosomal location of the StKPN $\beta$ genes in the DM1-3 potato genome (V4.3). ${ }^{\mathrm{d}}$ isomer numbers. ${ }^{\mathrm{e}}$ Length (number of amino acids), molecular weight(kilodaltons), and isoelectric point (pI) of the deduced polypeptides were calculated using Lasergene Molecular Biology Suite (Version 7.0). 

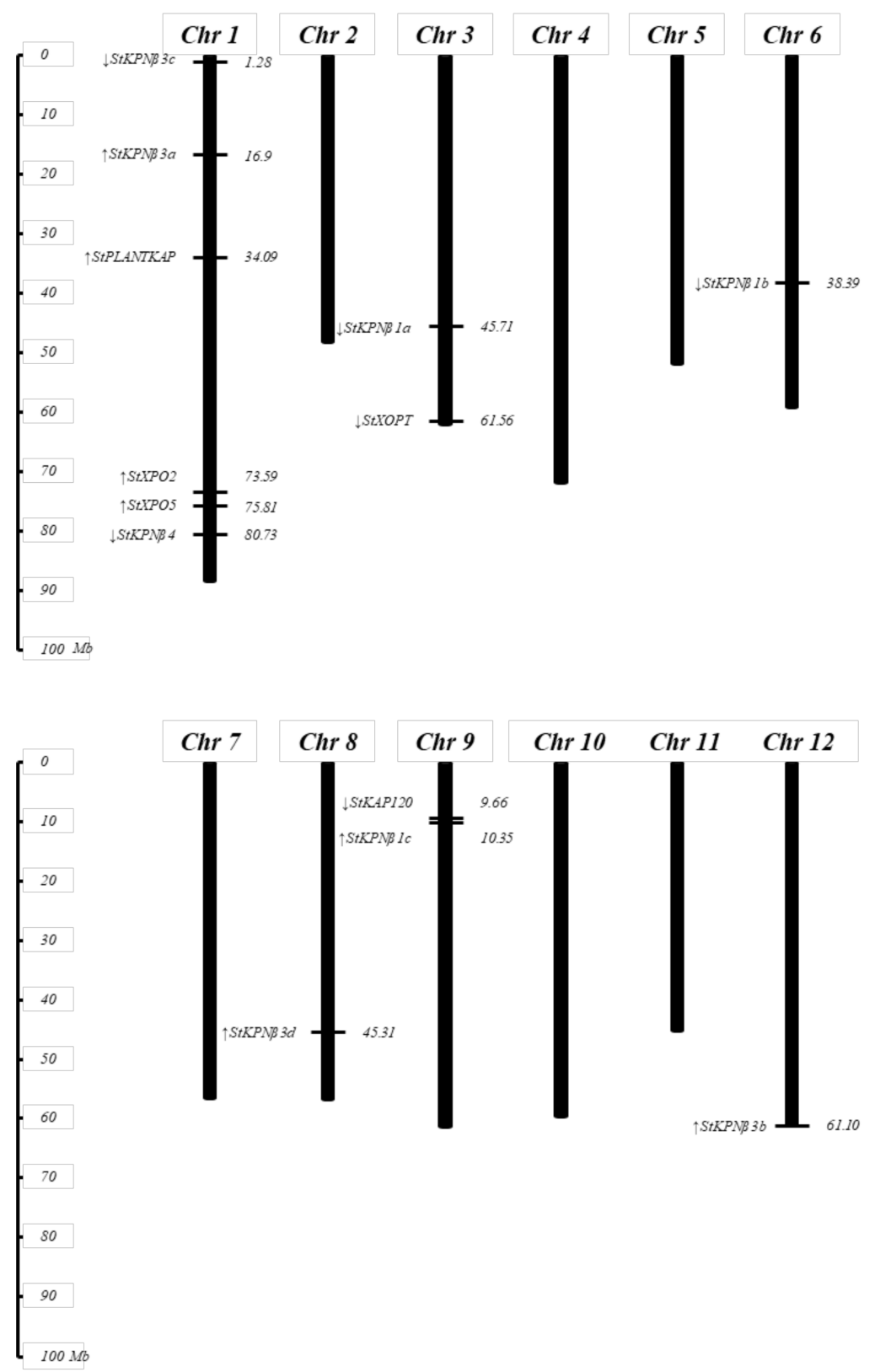

Figure 1. Genomic distribution of $S t K P N \beta$ genes on $S$. tuberosum group phureja DM1-3 chromosomes. The chromosome numbers and size are indicated at the top and bottom of each bar, respectively. The arrows next to gene names show the transcription directions. The number on the right side of the bars designated the approximate physical position of the first exon of corresponding StKPN $\beta$ genes on potato chromosomes.

\subsection{Gene Structure of StKPN $\beta$ S}

To better understand the gene structure of $S t K P N \beta$ s, the exon-intron features among members of StKPN $\beta$ family were aligned via phylogenetic analysis. The phylogenetic analysis revealed three clusters in accordance with the group data presented in Figure 2. Gene structure analysis of all StKPN $\beta$ genes suggested that the number of exons ranged from 2 to 20, except that $S t X P O 2$ is intronless gene. It is noteworthy that $S t K P N \beta$ members in KPN $\beta 1$ subfamily shares identical intron-exon structure. Three members of $S t K P N \beta 3$ subclade were also exhibits similar gene structure while $S t K P N \beta 3 c$ is a truncated gene. Although the exon-intron structure of $S t K P N \beta$ s varies between subclades, it is similar within subclades, which was supported by the phylogenetic analysis of StKPN $\beta$ proteins. 


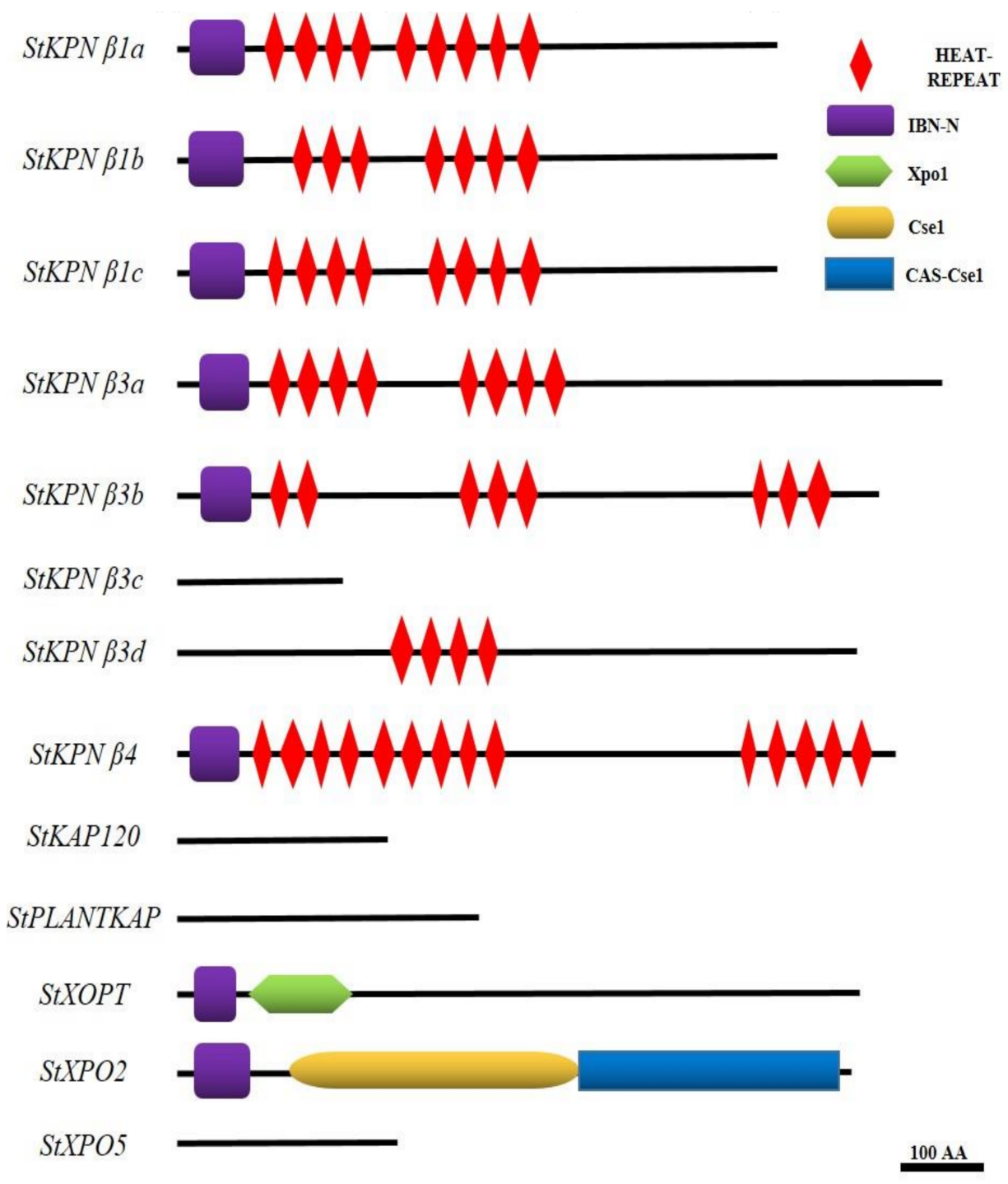

Figure 2. Analysis of conserved domains in StKPN $\beta$ proteins. Schematic organization of conserved domains in StKPN $\beta$ proteins. The IBN_N domain, HEAT repeats domain, XpoI amd CseI/CAS-CseI domain are shown in purple, red, green and yellow/blue, respectively.

\subsection{Conserved Domains and Motif Analysis of StKPNBs}

It is well-known that members of KPN $\beta$ proteins have common features-the IBN_N or XPO1 domains, and HEAT repeats. For members involved export of macromolecules, the conserved region was also called XPO1/CSE1 domains which contain HEAT repeats and a C-terminal domain. To better understand the structural similarity of potato $\operatorname{Imp} \beta$ s, we analyzed the amino acid sequences of $S t K P N \beta$ genes using CD-search available at NCBI with default configurations, and re-annotated the domains mentioned above. As shown on Figure 3, eight members of StKPN $\beta$ s contain both Heat repeat motif and IBN_N motif, and two members possess IBN_N and XPO1/CSE1 domains. There were three potato KPNBs with high sequence similarity to functionally characterized Arabidopsis karyopherins, in which no conserved domains were identified by CD-search. StKPN $\beta 3$, homologous to other StKPN $\beta 3$ genes, is truncated gene, which resulted in the loss of conserved domains aforementioned. 


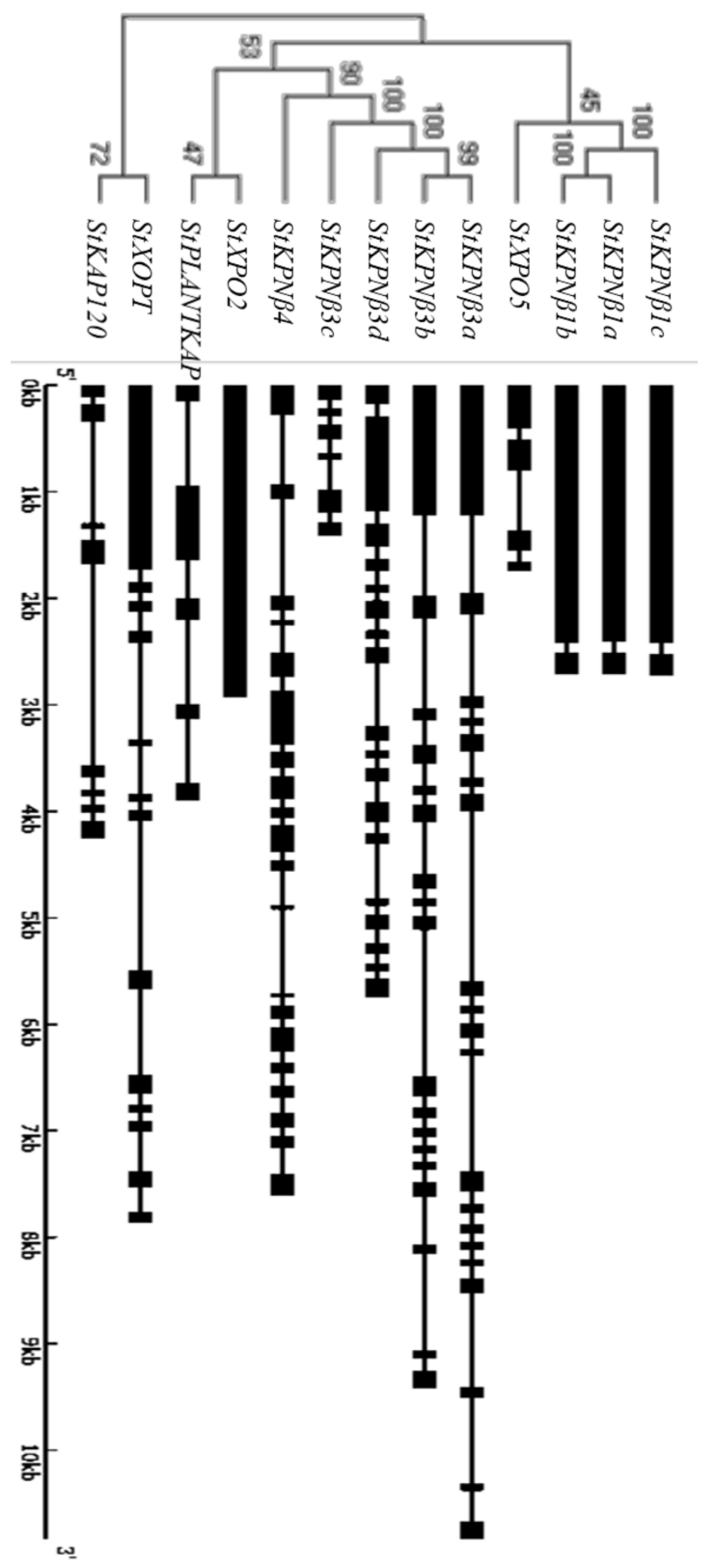

Figure 3. Classification of StKPN $\beta$ proteins. Neighbor-joining tree were generated using MEGA $X$ to determine the phylogenetic relationship between StKPN $\beta$ s (left). The intron-exon organization of StKPN $\beta$ genes was plotted using Gene Structure Display Server (Version 2.0). Black boxes represent exons and black lines represent introns (right).

In addition to the HEAT and IBN motifs, we searched the compositions of StKPN $\beta$ s, which was evaluated using the MEME suite (http://meme-suite.org/tools/meme), an online motif discovery tool. In our analysis, four novel conserved motifs were identified, and among the four motifs, motif I was present in all StKPN $\beta$ proteins; Motif II was identified in eight StKPN $\beta$ members; and motif III was found in 10 StKPN $\beta$ s (Figure 4), suggesting that these conserved regions might be essential to execute its biological functions. Furthermore, StKPN $\beta$ s in the same subfamily shared similar patterns of motif composition, indicating that their functional similarities. Thus, distribution of the motifs also reveals that StKPN $\beta$ s were likely conserved during the evolution. 

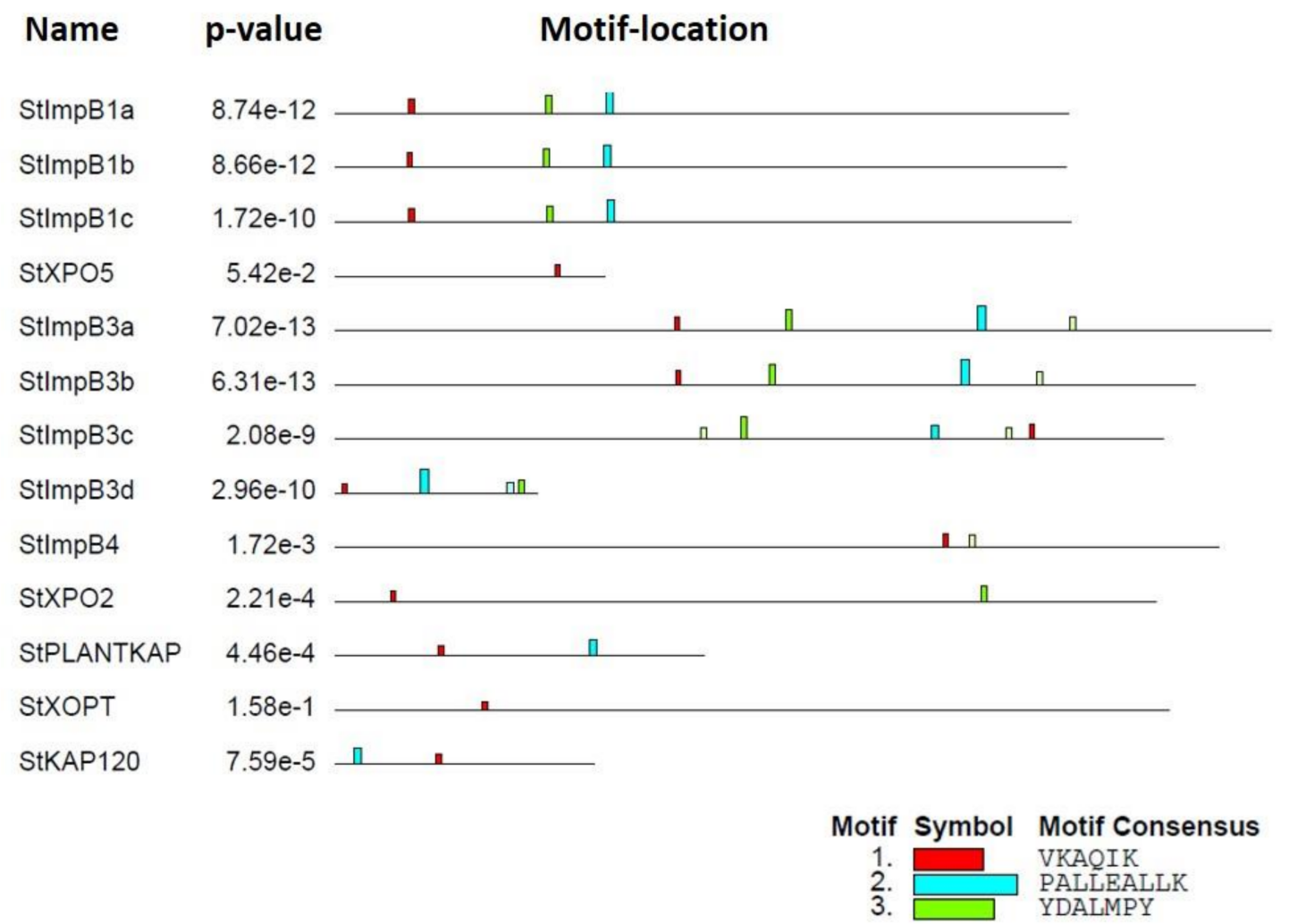

Figure 4. Conserved motifs embedded in the StKPN $\beta$ proteins. Conserved motif in StKPN $\beta$ s was evaluated using the MEME, and the location of novel motifs identified were designated in different colors.

\subsection{Phylogenetic Analysis of StKPNRS}

To investigate the phylogenetic relationship between the members of StKPN $\beta$ gene family, a neighbor-joining tree was constructed based on the multiple alignment of karyopherin $\beta$ protein sequences from A. thaliana, S. tuberosum, H. sapiens and S. cerevisiae. All these KPN $\beta$ proteins, in accordance with the human $\mathrm{KPN} \beta \mathrm{s}$, were allocated to 16 subfamilies with relatively high confidence (Figure 5). Multiple sequence alignment and phylogenetic analysis suggested that members of the KPN $\beta$ family were considerably diverged as the statistical support for some branches was relatively poor. Although yeast is a unicellular organism, at least $13 \mathrm{KPN} \beta \mathrm{s}$ were identified previously in $S$. cerevisiae. These yeast karyopherins included in our analysis actually represented 14 subfamilies of KPN $\beta$ nucleocytoplasmic transporters, strongly suggesting that the functional diversification of KPN $\beta$ had occurred. Moreover, two yeast KPN $\beta s$ (NMD5-SXM1), in our phylogenetic tree (Figure 5), were clustered into a sister pair, probably implying they were evolved from a common ancestor. Taken together, the results reinforced that the establishment of KPN $\beta$ family predated the appearance of radiation of eukaryote organism, which agrees well with conclusion drawn by O'Reilly et al. [16].

As shown on Figure 5, StKPN $\beta$ s were distributed into two sister pairs of paralogous Imp $\beta$ s (StKPN $\beta 1 a / 1 b / 1 c$, StKPN $\beta 3 a / 3 b / 3 c / 3 d$ ) with strong bootstrap support, while the other six form sister pairs with their Arabidopsis orthologs. Surprisingly, no potato ortholog could be detected in several KPN $\beta$ subfamilies including KPNB2/IMB2, KPNB5/IMB5, IPO8, XPO1, XPO4, XPO7 and TNPO3, whereas XOPT subfamily is the only one that was lost in Arabidopsis. The fact that, compared with yeast and Arabidopsis, there are fewer members in the potato KPN $\beta$ family reinforces that gene loss occurred after the divergence between Brassicaceae and Solanaceae. Notably, a lineage-specific subclade consisted with two KPN $\beta$ members from potato and Arabidopsis was detected, suggesting that they might represent a group of plant-specific nucleocytoplasmic transporters. The likely interpretation for 
the absence of XPO4 and XPO7 subclades from yeast genome indicates that in addition to PLANTKAP subclade, they were derived in multicellular organisms.

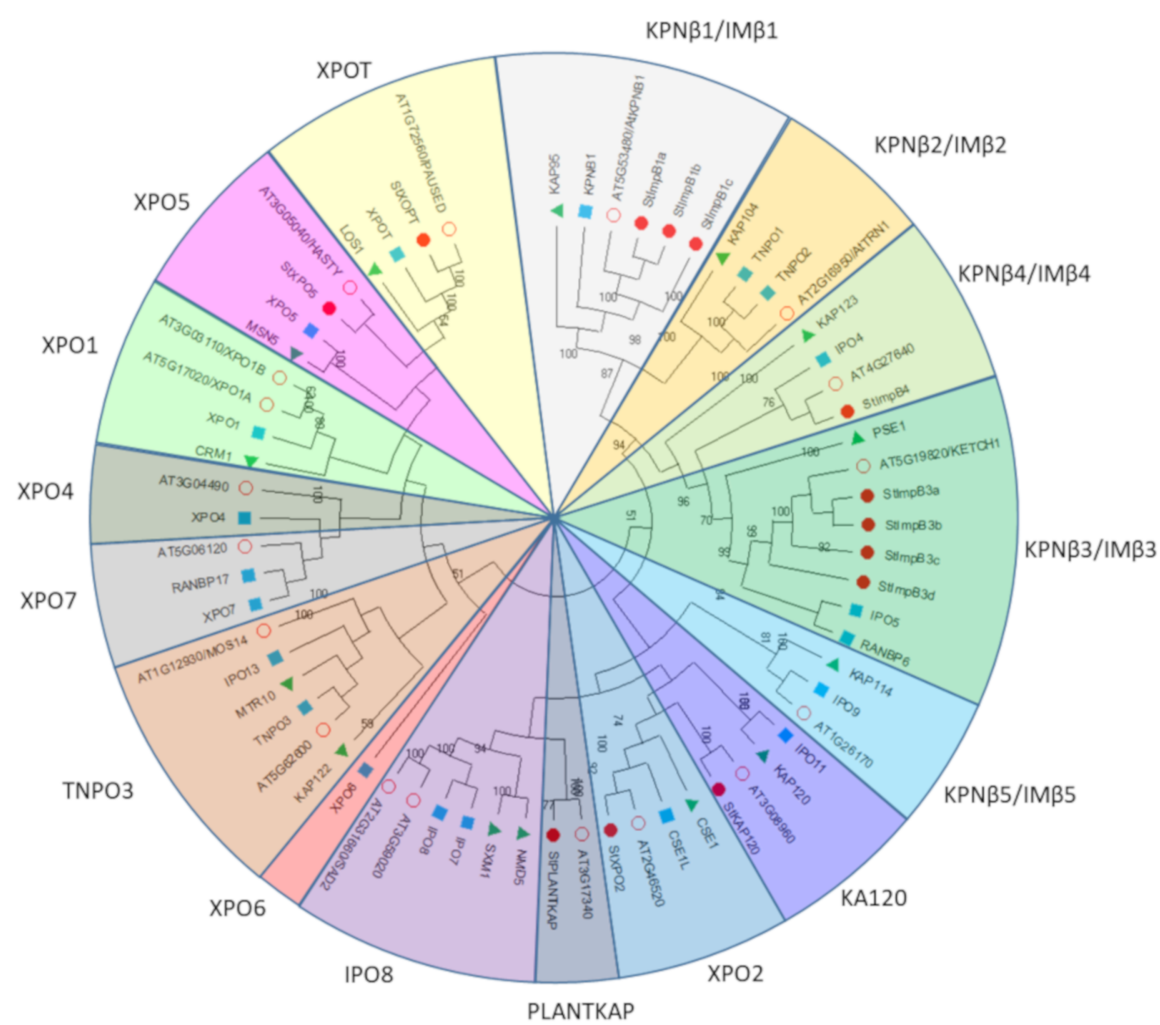

Figure 5. Phylogenetic analysis of StKPN $\beta$ proteins in A. thaliana, S. tuberosum, S. cerevisiae and $H$. sapiens. Neighbor-joining tree was constructed based on the alignment of KPN $\beta$ protein sequences from S. cerevisiae (Green triangle), H. sapiens (Blue square), A. thaliana (Red empty circle) and S. tuberosum (Red circle). The percent bootstrap support for 500 replicates is shown on each branch with $>50 \%$ support.

\subsection{Expression Profiles of StKPNßs among Various Tissues and Developmental Stages}

To gain the insight into the tissue- or organ-specific expression preferences of $S t K P N \beta$ genes, we analyzed the transcriptome data from Illumina RNA-Seq reads generated and stored by PGSC. The transcript abundance of $13 S t K P N \beta$ genes was determined from the RNA-Seq data as FPKM (Fragments per Kilobase of transcript per Million mapped reads) values. The RNA-seq database was generated from 16 tissues which could be divided into three major groups: floral (carpel, stamen, petal, sepal and mature flower), vegetative (leaf, leaflet, shoot, roots, tuber and stolon) and other tissues (callus) [31]. Digital gene expression analysis revealed that, among these $20 S t K P N \beta$ genes, StKPN $1 a / 1 b / 3 a$, StKAP120, StXPO5 were ubiquitously and robustly expressed in all tissues, suggesting that these StKPN $\beta$ s might execute some universal roles and participate nucleocytoplasmic transport in various tissues and organs; conversely, the expression level of $S t K P N \beta 3 d$ and StKPN $\beta 4$, compared to other StKPN $\beta$ s, was relatively lower, suggesting that these KPN- $\beta$ s might be unnecessary in normal growth conditions (Figure 6). Strikingly, transcripts of $S t K P N \beta 1 a / 3 a / 3 c$ were relatively abundant in tuber or stolon tissues, indicating that their possible association with potato tuber development. These results suggest that, as nucleocytoplasmic regulators, members of StKPN $\beta$ family have diverse roles of in potato floral and vegetative tissues. 


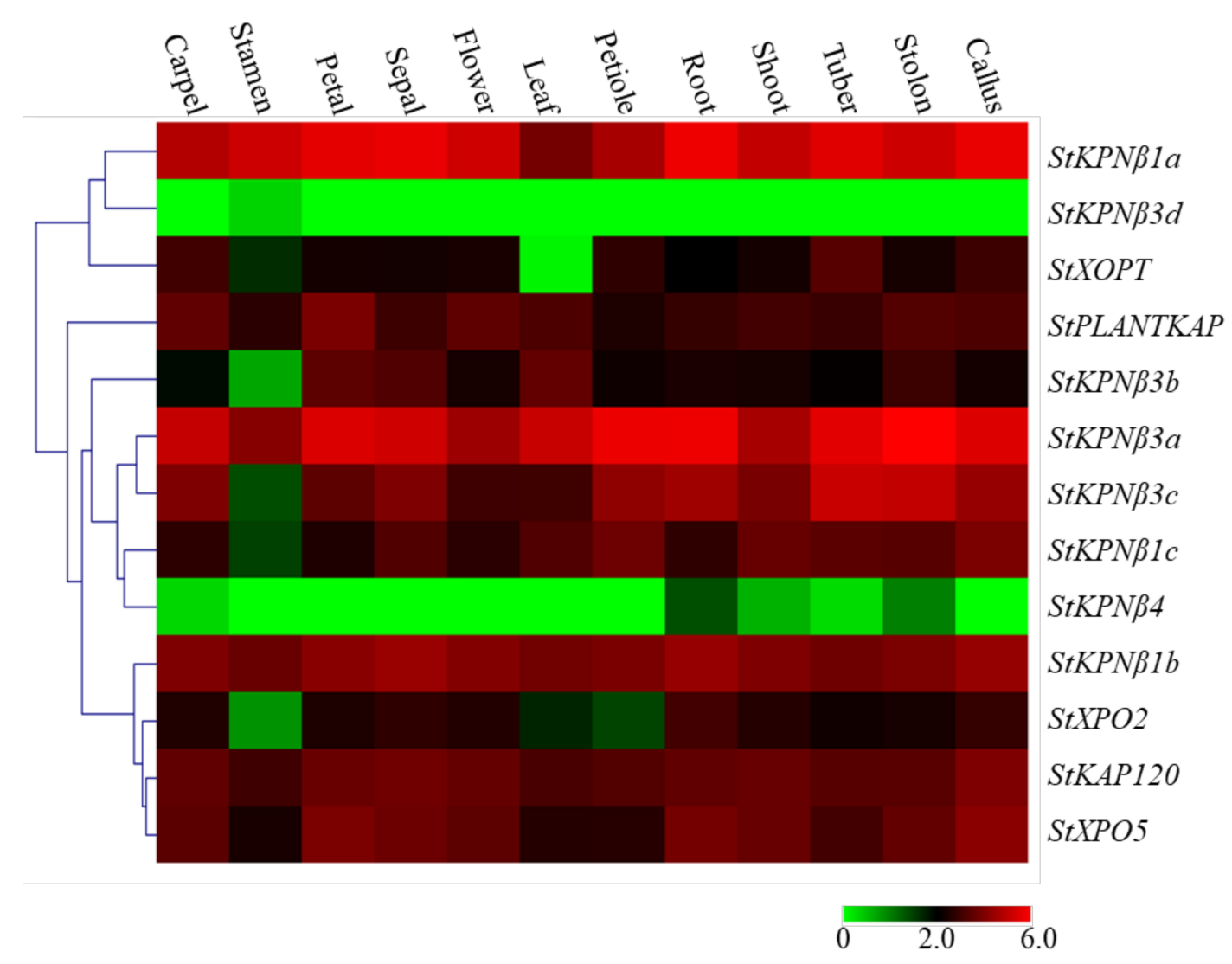

Figure 6. Expression profiles of StKPN $\beta$ genes with hierarchical clustering in different tissues. The Illumina RNA-Seq data were obtained from PGSC database, and the FPKM value of representative transcripts of StKPN $\beta$ s were used to generate heatmap with hierarchical clustering based on the Manhattan correlation with average linkage using $\mathrm{MeV}$ software package. Color scale below heatmap shows the expression level; red indicates high transcript abundance while green indicates low abundance.

\subsection{Expression Profiles of StKPN $\beta$ s in Response to Biotic and Abiotic Stresses}

To understand the functions of $S t K P N \beta$ genes under various stresses, the transcript abundance of 13 StKPN $\beta$ genes was analyzed the $\log 2$ fold change between treatments and controls. RNA-Seq data revealed that most $S t K P N \beta$ s were found to be significantly induced by at least one treatment, while the $S t K P N \beta 3 b$ transcript was not affected by stress conditions (Figure 7a). Of these 13 StKPN $\beta$ genes, StKPN $\beta 4$ increased by 2.63-fold under high salinity, and 2.21-fold in response to mannitol stress, while $S t K P N \beta 3 d$ exhibited a high level of transcription abundance under mannitol and wounding stresses, with 1.90-fold and 1.81-fold increase, respectively. The expression of StXPO2 and StXPO5 was increased in response to both salt and wounding treatments. These results suggest that StKPN $\beta$ s might be serve as core regulators in mediating the signaling transduction of abiotic stresses.

Several $S t K P N \beta$ genes were found to be induced by at least one stress condition (Figure 7a). For example, StPLANTKAP were increased by 1.83 -fold under salt stress, while in response to wounding treatment, StKPN $\beta 1 c, S t K P N \beta 3 c$ and StXOPT were highly increased by 1.94-, 2.15- and 2.30 -fold, respectively. The expression specificity of these $S t K P N \beta$ s indicates that they were functionally diverged and actively regulated trafficking of different responsive proteins across the nuclear membrane. It seems that most StKPN $\beta$ s did not respond to thermal and Phytophtora infestans (Mont.) de Bary challenges. The oomycetes $P$. infestans infection resulted in the 1.48-fold expression increase of StXOPT, suggesting it might involve the process of plant defense against the pathogen. Therefore, this result suggests that StKPN $\beta$ s are associated with plant responses to abiotic and biotic stresses. 
هـ
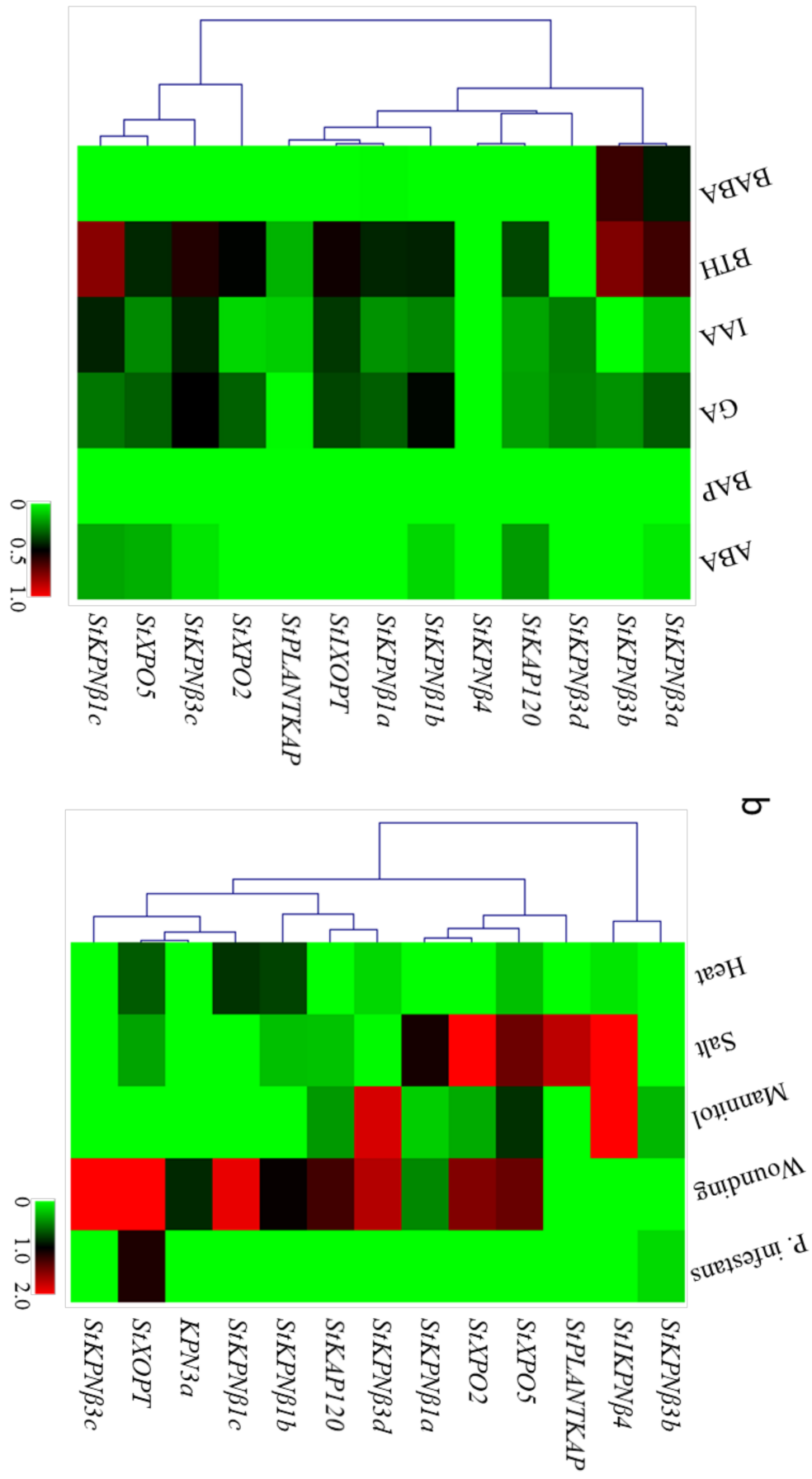

Figure 7. Heatmap representation and hierarchical clustering of StKPN $\beta$ genes under abiotic and biotic stresses (a) and phytohormone treatments (b). The Illumina RNA-Seq data were obtained from PGSC database, and the relative expression of $S t K P N \beta$ genes was calculated with respect to control samples using FPKM values of representative transcripts corresponding to $S t K P N \beta$ genes. Fold changes of $S t K P N \beta$ expression were $\log _{2}$ transformed, and the normalized expression data was used to generate heatmap with $\mathrm{MeV}$ software package using the same parameters in Figure 6. Color scale below heatmap shows the expression level; red indicates high transcript abundance, while green indicates low abundance. 


\subsection{StKPNßs Response to Various Phytohormones}

Similarly, we also examined the expression changes of $S t K P N \beta$ s under different phytohormone or chemical analog treatments by RNA-Seq and quantitative real-time RT-PCR (qRT-PCR) analysis. An interesting observation from RNA-Seq analysis was that expression level of a majority of $S t K P N \beta$ genes were decreased when potato plant being treated with phytohormones or their analogs (Figure $7 \mathrm{~b}$ ). When plants treated with benzothiadiazole S-methyl ester (BTH), a chemical analog of salicylic acid, transcript accumulation of StKPN $\beta 1 c, S t K P N \beta 3 a$ and StKPN $\beta 3 b$ genes was observed, suggesting their upregulation possibly contributes to the plant defenses to pathologies. Application of DL- $\beta$-amino-n-butyric acid (BABA), known as a disease resistance-priming agent, resulted in the weak induction of StKPN $\beta 3 b$.

Although Illumina RNA-Seq data provides plenty of information on the expression profiles of $S t K P N \beta$ genes, we still lack their expression behavior in response to some important signal molecules such as ethylene (ETH), jasmonic acid (JA), hydrogen peroxide $\left(\mathrm{H}_{2} \mathrm{O}_{2}\right)$ and salicylic acid (SA). Thus, quantitative real-time RT-PCR (qRT-PCR) analysis was employed to determine the expression patterns of $S t K P N \beta$ genes in these phytohormones or chemicals, and leaf tissues of potato treated with $50 \mu \mathrm{M} \mathrm{SA}, 1 \mathrm{mM} \mathrm{JA}, 1 \mathrm{mM}$ ETH and $50 \mu \mathrm{M} \mathrm{H}_{2} \mathrm{O}_{2}$, respectively, were used in the experiments.

Most $S t K P N \beta$ genes considered in this study were upregulated upon SA, ETH or JA treatments. Compared to the controls, SA-feeding promoted the expression increase of StKPN $\beta 1 a / 3 a$ and StXOPT by at least 6.5 -fold under $24 \mathrm{~h}$ SA treatment, and similarly StKPN $\beta 1 \mathrm{~b} / 3 \mathrm{~b} / 3 c / 3 c / 4$ and StPLANTKAP also exhibited moderately increases, which suggested that they might be involved in the SA-signaling pathway. In JA-feeding experiments, all $S t K P N \beta$ genes displayed an enhanced level of transcript abundance after $4 \mathrm{~h}$ treatment, indicating their potential roles in JA-mediated signal transduction. After $4 \mathrm{~h}$ ETH treatments, expression of $S t K P N \beta 1 b / 3 c / 3 d$ were strongly activated by ethylene, with 24.0-, 25.8- and 39.9-fold expression increases, respectively; yet, other StKPN $\beta$ s were slightly induced (Figure 8).

Hydrogen peroxide, predominantly produced during photosynthesis, photorespiration or respiration processes, plays an essential role as signaling molecule in numerous physiological process. The members of $S t K P N \beta$ gene family were simply classified into two groups according to their responsive behavior in response to $\mathrm{H}_{2} \mathrm{O}_{2}$ upregulated and downregulated. The first group represents StKPN $\beta$ genes that were induced by $\mathrm{H}_{2} \mathrm{O}_{2}$ and correspond to StKPN $\beta 1 a / 1 c / 3 a$, StPLANTKAP and $S t X O P T$, while the second group includes the remaining StKPN $\beta$ s, of which the expression negatively responded to $\mathrm{H}_{2} \mathrm{O}_{2}$ (Figure 8). The observations imply that they may be important components of the Reactive oxygen species (ROS) signal cascade in plants. Collectively, these results indicate that StKPN $\beta$ s were associated with diverse signaling pathways and probably were one of major players in environmental stress and immunity system. 


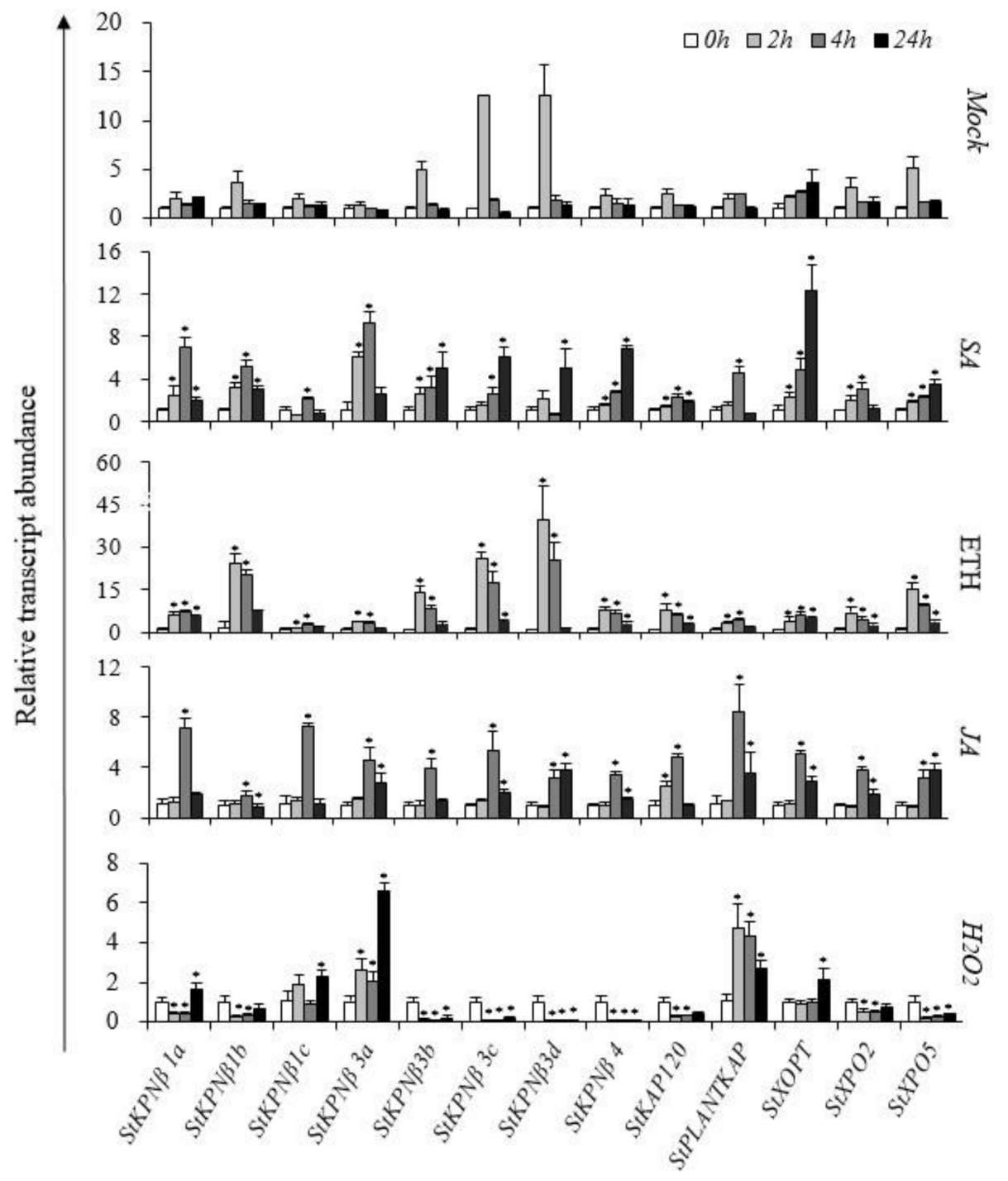

Figure 8. qRT-PCR analysis of $S t K P N \beta$ genes in response to salicylic acid (SA), ethylene (ETH), jasmonic acid (JA) and hydrogen peroxide $\left(\mathrm{H}_{2} \mathrm{O}_{2}\right)$. StKPN $\beta$ transcript levels measured by real-time RT-qPCR from the various tissues or under phytohormone treatments at indicated time points. Data are means of three biological replicates (eight pooled plants each), and error bars denote SE. The StACT gene was used as an internal control. Stars above the error bars indicate significant differences between treatments and controls (according to student's t-test). qRT-PCR primers for each StKPN $\beta$ genes were provided in Table S1.

\subsection{Knockdown of StKPN $\beta 3$ a Expression Results in Increased Susceptibility to Environmental Stresses}

Considering that expression of some $S t K P N \beta$ was activated by various stress or hormone treatments, it is plausible that silencing of positively responsive $\mathrm{KPN} \beta \mathrm{s}$ would impair the plant tolerance to environmental stresses. Thus, VIGS approach was employed to investigate the role of potato KPN $\beta$ s. As StKPN $\beta 3 a$ was one of highly expressed, $\mathrm{H}_{2} \mathrm{O}_{2}$ - and SA-inducible genes, it was chosen for the insertion into the viral vector pGR107 (PVX), and the resulting plasmid PVX-StKPN $\beta 3 a$ was introduced into Agrobacterium containing the helper plasmid pJIC SA-Rep. The Agrobacterium lines harboring PVX-StPDS and empty PVX vector (PVX00) were served as controls. Potato plants were transformed by leaf-injection with Agrobacterium lines aforementioned, and after one month, all silencing lines were verified by qRT-PCR method. We found that leaves of PVX-StPDS lines exhibited photo-bleaching phenotypes, which was agreed with the reduction of StPDS genes. Compared to the control plants, 
transcript accumulation of $S t K P N \beta 3 a$ was decreased in $S t K P N \beta 3 a$-sliciencing lines, whereas expression of $S t K P N \beta 3 b$, StKPN $\beta 3 c$ and $S t K P N \beta 3 d$ were not significantly affected (Figure $9 \mathrm{~b}$ ), suggesting that $S t K P N \beta 3 a$ expression was specifically turn down. Under normal conditions, StKPN $\beta 3 a$-sliciencing lines did not exhibit any morphological changes compared to the control plants (Figure 9c). Subsequently, the leaf discs of $S t K P N \beta 3 a$-sciliencing as well as experimental controls were floated on the distilled water supplemented with $300 \mathrm{mM} \mathrm{NaCl}$ or $100 \mu \mathrm{M} \mathrm{H} \mathrm{H}_{2} \mathrm{O}_{2}$. After 48 -hr salt or $\mathrm{H}_{2} \mathrm{O}_{2}$ treatments, we observed that, compared to the PVX00 controls, leaf discs of PVX-StKPN $\beta 3 a$ lines suffered severe damages (Figure 9a), while there were no evident morphological changes in leaf discs of non-silenced controls. The results illustrated that repression of $S t K P N \beta 3 a$ could lead to the increased susceptibility to abiotic stresses.

a
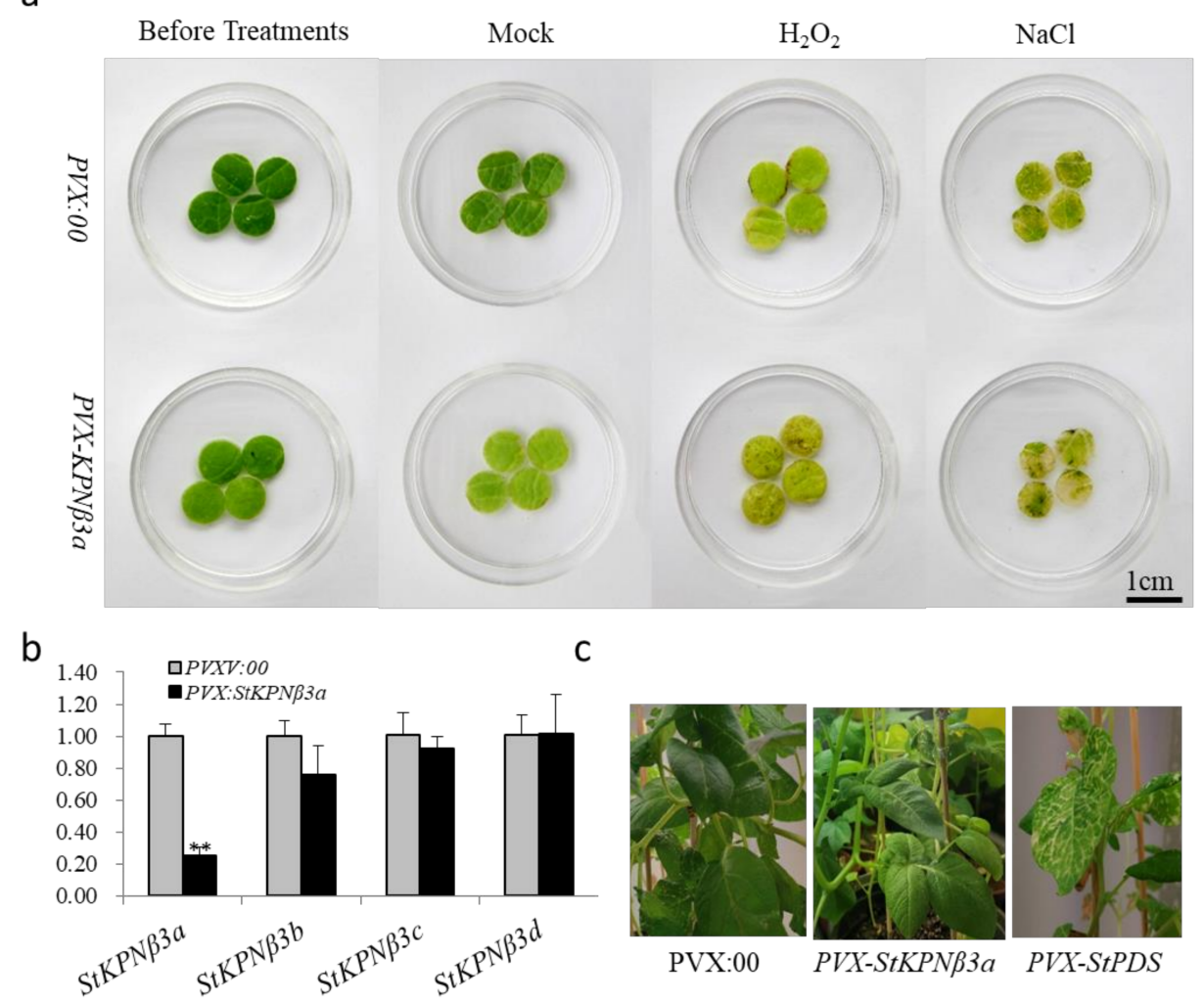

Figure 9. StKPN $\beta 3 a$-silenced potato plants exhibit reduced resistance to salt and $\mathrm{H}_{2} \mathrm{O}_{2}$ treatments. Potato plants were infiltrated with Agrobacterium carrying VIGS-control vector (PVX:00) and PVX-StKPN $\beta 3 a$, and after 2-3 weeks, the StKPN $\beta 3 a$-silencing lines confirmed by qRT-PCR were used for leaf-disk assay. (a) Leaf-disk assay for plant tolerance to different abiotic stresses. (b) Expression analysis of StKPN $\beta 3$ members in StKPN $\beta 3 a$-silencing and control lines. (c) Phenotype of PVX-StKPN $33 a$-Silencing and control potato plants. The photographs were taken before or after 48 -hrs salt $(300 \mathrm{mM})$ or $\mathrm{H}_{2} \mathrm{O}_{2}$ $(100 \mu \mathrm{M})$ treatments, respectively. qRT-PCR analysis of StKPN $\beta 3 a$ expression in cotton plants infiltrated with VIGS-control vector (PVX:00) and PVX-StKPN $33 a$. Error bars indicate SD from three technical replicates of three biological experiments, and asterisks indicate statistically significant differences, as determined by the Student's t test $\left.{ }^{* *}, p<0.01\right)$. The experiments were repeated three times with similar results.

\section{Discussion}

Karyopherin/Importin $\beta$, as an essential nucleocytoplasmic transport receptor, is considered to be a global regulator of diverse cellular functions, ultimately affecting the growth, development and stress adaptions of the eukaryotes [32]. However, current knowledge on its characteristics of was largely obtained from functional characterization of animal and yeast $K P N \beta$ genes. In the past 
two decades, achievements have been made in understanding the role of KPN $\beta$ in model plant $A$. thaliana, and several KPN $\beta$ genes, including Hasty, SAD2/EMA1, AtKPNB1, MOS14 and KETCH1, were investigated in detail, demonstrating their vital roles involved in the Arabidopsis development, biotic and abiotic stresses [21,22,33-36]. However, the identification and functional analysis of KPN $\beta$ homologs still limited in plants other than Arabidopsis. Hence, analyses of KPN $\beta$ gene family in $S$. tuberosum become indispensable in understanding of its gene structure, protein function and evolution.

The number of $K P N \beta$ genes varies among organisms. In the study, $13 K P N \beta$ genes were identified from potato genome, whereas previous search identified $18 \mathrm{KPN} \beta \mathrm{s}$ in Arabidopsis [20,31]. Considering that potato has undergone two rounds of whole-genome duplication (WGD) events so that the genome size of DM1-3 potato was nearly five times larger than Arabidopsis [26], the observations on StKPN $\beta$ gene family contradicted with genome complexity between potato and Arabidopsis. Therefore, it is interesting that the number of $S t K P N \beta$ genes was much less than that of Arabidopsis. Our phylogenetic analysis revealed that eight KPN $\beta$ subfamilies, namely $K P N \beta 1 / \operatorname{IM} \beta 1, K P N \beta 3 / \operatorname{Imp} \beta 3, K P N \beta 4 / \operatorname{Imp} \beta 4$, KA120, PLANTKAP, XPO2, XPO5 and XOPT, were represented by at least one KPN $\beta$ ortholog in potato genome, and duplication events occurred only in KPN $\beta 1$ and KPN $\beta 3$ subfamilies, perhaps due to the independent, small-scale, segmental duplication events and chromosome rearrangements in the two loci. Nevertheless, in comparison to yeast and Arabidopsis, it seems that homologs to other seven

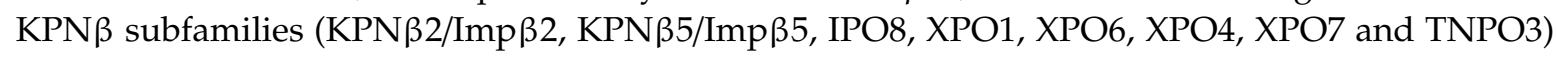
were lost completely during the evolution in potato genome, consequently resulting in the fewer members of KPN $\beta$ in potato genome.

Functional redundancy and diversification were observed in potato $K P N \beta 1 / \operatorname{Imp} \beta 1$ and KPN $\beta 3 / I m p \beta 3$ gene subfamilies. With respect to KPN $\beta 1$ subfamily, phylogenetic analysis and sequence alignment revealed the existence of three genes, namely StKPN $\beta 1 a$, StKPN $\beta 1 b$ and StKPN $\beta 1 c$, homologous to AtKPNB1, which raises the possibility that these StKPNB1s might execute similar functions. Consistent with the assumptions, we found that expression patterns under stress or phytohormone treatments, to a large extent, resembled among members of StKPN $\beta 1$, implying that members of StKPNB1s might share some conserved and overlapping functions. Nevertheless, it was noteworthy that some expression discrepancies between $S t K P N \beta 1$ genes, because expression analysis demonstrated that only $S t K P N \beta 1$ a could not respond to wounding stress, while expression of $S t K P N \beta 1 \mathrm{c}$, instead of $S t K P N \beta 1 \mathrm{a}$ and $S t K P N \beta 1 \mathrm{~b}$, was able to be strongly activated by wounding treatment, which reflects that members of $S t K P N \beta 1$ subfamily might have acquired its unique roles through functional diversifications.

Recent investigations have reported that a few Arabidopsis KPN $\beta / \operatorname{Imp} \beta$ s, as nucleo-cytoplasmic transport receptors, are involved in stress adaption under abiotic and biotic stresses, while they are not stress-inducible genes [20,37]. AtKPNB1 encodes an ortholog of human KPNB1 in Arabidopsis, and kpnb1 loss-of-function mutant exhibits increased sensitivity to ABA [20]. It was proven that AtKPNB1, functioning as negative regulator, could regulate the ABA responses and drought tolerance via ABI1- and ABI5-independent pathways, though ABA treatment only slightly boosted the transcript accumulation of AtKPNB1 [24]. In addition, absence of SAD2 (Super sensitive to ABA and Drought 2), member of IPO8 subfamily, led to the enhanced sensitivity to ABA, $\mathrm{H}_{2} \mathrm{O}_{2}$ or drought in Arabidopsis, whereas its expression was independent from phytohormone or stress treatments [37,38]. In agreement with previous findings, our RNA-Seq analysis also suggested that many members of StKPN $\beta$ gene family did not show any transcriptional responses to hormones or stresses examined, and only several StKPN $\beta$ s, such as StKPN $\beta 3 d$, StKPN $33 b$, StPLANTKAP, StXOPT etc., were able to respond to environmental cues or phytohormone inductions.

It is tempering to analyze the roles of responsive StKPN $\beta$ s, especially whose expression could be activated by hormones, environmental cues or pathogen infections. Expression of StKPN $\beta 3 a$ was strongly induced by SA, JA or $\mathrm{H}_{2} \mathrm{O}_{2}$ treatments, suggesting its involvements in the phytohormone cascades. Thus, using VIGS approach, we demonstrated that silencing of StKPN $\beta 3 a$ resulted in the increased susceptibility to salt or oxidative stresses, supporting that its function is indispensable 
in the stress signaling transductions. However, due to the lack of stable transgenic lines of StKPN $\beta 3 a$-overexpression or -RNAi, the biological functions of StKPN $\beta 3 a$ still need to be investigated in detail. Phylogenetic analysis supported that StKPNB3a were orthologous to yeast PSE1/Kap121, human IPO5 and RANBP6. Yeast strains with disruption of PSE1 functions exhibit delayed mitosis and enhance sensitivity to temperature stress, while overexpression PSE1 contributes to the three-fold increase of cellulose production [39-41]. The import of histone $\mathrm{H} 2 \mathrm{~A} / \mathrm{H} 2 \mathrm{~B}$ and $\mathrm{H} 3 / \mathrm{H} 4$ is mainly mediated by PSE1 in S. cerevisiae, suggesting its essential roles in intranuclear transport [42,43]. It has been demonstrated that human IPO5 also functions in the nuclear import of essential histones as well as some ribosomal proteins [44]. Given that members of Imp $\beta 3$ subclades play key roles in nucleocytoplasmic trafficking, it is reasonable that $S t K P N \beta 3 a$ might execute the similar roles by regulating the import of positive regulatory protein(s) under abiotic stresses. Further investigations will be still required to identify its cargo(s) and to articulate the molecular mechanism of $\operatorname{Imp} \beta$-mediated signaling pathway in plants.

\section{Materials and Methods}

\subsection{Plant Material and Treatments}

S. tuberosum Phureja DM1-3 or cultivar "Shpedy" plants were in vitro micropropagated on Murashige and Skoog (MS) medium plus $30 \mathrm{gL}^{-1}$ sucrose and $0.8 \%$ agar (Sigma-Aldrich, USA), with $\mathrm{pH}$ adjusted to 5.8. Potato seedlings were routinely subcultured as two-node segments every $3-4$ weeks and incubated at $23^{\circ} \mathrm{C}$ with $16 \mathrm{~h}$ photoperiod under cool with fluorescent lamps $\left(\sim 70 \mu \mathrm{mol} \mathrm{m}{ }^{-2} \mathrm{~s}^{-1}\right.$ photon flux idensity). 3-week old potato plants were subjected to IAA $(50 \mu \mathrm{M}), \mathrm{SA}(1 \mathrm{mM})$, ethylene $(1 \mathrm{mM})$ or $\mathrm{H}_{2} \mathrm{O}_{2}(1 \mathrm{mM})$ treatments. The plant tissues were collected at designated points and immediately frozen in liquid nitrogen. Sample collections were performed on separate days for the replicates.

\subsection{Identification of KPN $\beta$ Genes in S. tuberosum Group Phureja}

To investigate the KPN $\beta$ gene family in in S. tuberosum Group phureja DM1-3, all members of $\mathrm{KPN} \beta / \operatorname{Imp} \beta$ sequences from Human (H. sapiens), yeast (S. cerevisiae) and Arabidopsis were used as queries for BLAST search against Phytozome (https://phytozome.jgi.doe.gov/), NCBI (http://blast.ncbi. nlm.nih.gov/), Potato Genomics Resource (http://solanaceae.plantbiology.msu.edu/) and other online resources with default parameters. The StKPN $\beta$ candidates were confirmed the presences of IBN_N (PF08310) or XpoI (PF08389) domain, and HEAT repeats using SMART (http://smart.embl-heidelberg. de/smart/batch.pl) and CDD-search. In order to obtain non-redundancy KPN $\beta$ sequences, potato KPN $\beta$ sequences were used as queries to blast against Phytozome database, and any redundancy was manually removed. The representing gene model per $S t K P N \beta$ locus were identified and their corresponding information on chromosomal location, locus ID, transcript ID were obtained simultaneously.

\subsection{Analysis of Gene Structure and Conserved Domains}

Based on the genome annotation of DM assembly available in Phytozome, the intron-exon structure of individual $S t K P N \beta$ genes was predicated, and its genomic organization was visualized using Gene Structure Display Server 2.0 (GSDS, http://gsds.cbi.pku.edu.cn/) [45]. Conserved domains in protein sequences were verified using ScanProsite (http://pro-site.expasy.org/scanprosite/), which provides information about positions of different domains in the protein sequence. This information was used to draw visual representation of distribution of domains in the deduced amino acid sequences of proteins using Microsoft Office PowerPoint 2016.

\subsection{Sequence Alignment and Phylogenetic Construction}

Multiple alignment of KPN $\beta$ protein sequences from A. thaliana, S. tuberosum, H. sapiens and S. cerevisiae was conducted using ClustalW [46]. Neighbor-joining method was used to conduct a phylogenetic tree analysis in MEGA X, with 500 bootstrap replicates and randomized sequence input order. 


\subsection{Expression Profiling of StKPN $\beta$ Genes in Different Tissues or Under Various Stresses}

The RNA-Seq data corresponding to $S t K P N \beta$ genes was downloaded from the Potato Genomics Resource [31], and the corresponding FPKM (fragments per kilobase per million reads) values for $S t K P N \beta$ genes were obtained for 12 tissues representing major organs and developmental stages, including floral (carpel, petals, sepals, stamens and mature flower), leaf (whole leaf, leaflet and petiole), tuber (tuber and stolon), and other organs (shoot, root and callus). As described, biotic and abiotic treated tissues included potato plants exposed to heat $\left(35^{\circ} \mathrm{C}\right), \mathrm{NaCl}(150 \mathrm{mM})$ or Mannitol $(260 \mathrm{mM})$, and leaves challenged by P. infestans, BABA (DL- $\beta$-amino-n-butyric acid), BTH (6-benzylaminopurine) or hormones [31]. Similarly, FPKM values for abiotic or biotic stress-treated potato plants were analyzed by calculating the fold change of expression levels between treatments and the corresponding controls. The normalized expression data was used to generate heatmap by using the $\mathrm{MeV}$ software package (http://mev.tm4.org) available at the Institute for Genomic Research, and hierarchical clustering analysis (HCA) was built on the basis of the Manhattan correlation with average linkage method.

\subsection{RNA Extraction and Quantitative Real-Time RT-PCR}

Total RNA was extracted with Trizol (Invitrogen Inc., Madison, WI, USA) as described previously [47,48]. RNA quantity and quality were assessed using a NanoDrop8000 (Thermo Scientific ${ }^{\mathrm{TM}}$, Wilmington, DE, USA). Total RNA isolation and reverse transcription with oligo (dT) 18 (18418-012; Invitrogen, Madison, WI, USA) were performed as described previously. The amounts of individual genes were measured with gene-specific primers by real-time PCR analysis with a cycler IQ real-time PCR instrument CFX96 and SYBR Green mixture (Bio-Rad, Foster City, CA, USA). The relative expression of specific genes was quantitated with the $2^{-\Delta \Delta C t}$ calculation method [49], where $\Delta \Delta C t$ is the difference in the threshold cycles and the reference housekeeping gene, which was potato StACT (PGSC0003DMG400027746) for expression analyses. The sequences of specific primers are shown in Table S1.

\subsection{Virus-Induced Gene Silencing (VIGS) of Potato}

The potato virus $X(P V X)$-induced gene silencing is conducted as described previously [50, 51]. Briefly, $P V X-S t K P N \beta 3$ a were generated by cloning a PCR fragment amplified by $S$. tuberosum phureja DM1-3 potato leaf cDNA template using specific oligonucleotide primers incorporating SalI and ClaI restriction sites, respectively, at the $5^{\prime}$ - and $3^{\prime}$-ends for cloning into virus vector pGR107. The Agrobacterium tumefaciens (Smith \& Townsend, 1907) strain GV3101 harboring the recombinant plasmids PVX-StKPN $\beta 3 a$ and help plasmid pJIC SA_Rep were used for in vitro agroinoculation by leaf-injecting of 4-week-old potato plants. The Agrobacterium lines carrying with PVX-StPDS and the PVX vectors were used as positive and negative controls, respectively. Primers used for RT-PCR amplifications are listed in Table S1.

\section{Conclusions}

In this study, the systematic characterization of $K P N \beta / \operatorname{Imp} \beta$ gene family was performed in the S. tuberosum. A total of 13 StKPN $\beta$ genes were identified through searching potato genome, and their chromosomal distribution, conserved domain, motif composition and intron-exon structure were studied in detail. Expression analysis based on the RNA-Seq and qRT-PCR analysis suggested that several $S t K P N \beta s$ was responsive to biotic and/or abiotic stresses. Furthermore, the function of $S t K P N \beta 3 a$ was characterized through VIGS approach, illustrating that it might be a promising candidate gene for molecular breeding. In summary, our results provide valuable insights of $S t K P N \beta$ s gene family, which will facilitate further functional analysis of $S t K P N \beta s$ and will also benefit genetic engineering of potato.

Supplementary Materials: Supplementary materials can be found at http://www.mdpi.com/1422-0067/21/3/931/s1.

Author Contributions: Conceptualization, N.L.; Methodology, N.L.; Investigation, Y.X., L.L., P.Z. and N.L.; Data analysis, Y.X., J.T. and N.L.; Project administration, N.Z. and H.Z.; Funding acquisition, N.L. and N.Z..; 
Supervision and Manuscript preparation, N.L. All authors have read and agreed to the published version of the manuscript.

Funding: This project was supported by the National Key Research and Development Program of China (2017YFD0200708), the Key Innovation of Science and Technology of Shandong province in China (2018CXCC0303), the Science Transfer and Service (KFJ-STS-ZDTP-056) of Chinese Academy of Sciences, the Key Research and Development Program of Ningxia Autonomous Region in China (2018BBF02021), the National Natural Science Foundation of China (31601622) and the Young Talent Supporting Program (YCXTD0000210) of the Beijing Agricultural and Forestry Sciences.

Acknowledgments: We thank Prof. Guixian Xia (Institute of Microbiology, Chinese Academy of Sciences) and Prof. Zhanhui Wu (Vegetable Research Center, Beijing Academy of Agricultural and Forestry Sciences) for fruitful discussions on this manuscript. We also thank Prof. Jiahe Wu (Institute of Microbiology, Chinese Academy of Sciences) for kindly providing DM1-3 potato seedlings.

Conflicts of Interest: The authors declare no conflict of interest.

\section{References}

1. Baum, D.A.; Baum, B. An inside-out origin for the eukaryotic cell. BMC Biol. 2014, 12, 76. [CrossRef] [PubMed]

2. Lane, N.; Martin, W. The energetics of genome complexity. Nature 2010, 467, 929-934. [CrossRef] [PubMed]

3. Xu, X.M.; Meier, I. The nuclear pore comes to the fore. Trends Plant Sci. 2008, 13, 20-27. [CrossRef] [PubMed]

4. Fahrenkrog, B.; Aebi, U. The nuclear pore complex: Nucleocytoplasmic transport and beyond. Nat. Rev. Mol. Cell Biol. 2003, 4, 757-766. [CrossRef]

5. Fried, H.; Kutay, U. Nucleocytoplasmic transport: Taking an inventory. Cell Mol. Life Sci. 2003, 60, 1659-1688. [CrossRef] [PubMed]

6. Gorlich, D.; Mattaj, I.W. Nucleocytoplasmic transport. Science 1996, 271, 1513-1518. [CrossRef]

7. Goryaynov, A.; Yang, W. Role of molecular charge in nucleocytoplasmic transport. PLoS ONE 2014, 9, e88792. [CrossRef]

8. Oka, M.; Yoneda, Y. Importin alpha: Functions as a nuclear transport factor and beyond. Proc. Jpn. Acad. Ser. B Phys. Biol. Sci. 2018, 94, 259-274. [CrossRef]

9. Ullman, K.S.; Powers, M.A.; Forbes, D.J. Nuclear export receptors: From importin to exportin. Cell 1997, 90, 967-970. [CrossRef]

10. Yeon, S.I.; Youn, J.H.; Lim, M.H.; Lee, H.J.; Kim, Y.M.; Choi, J.E.; Lee, J.M.; Shin, J.S. Development of monoclonal antibodies against human IRF-5 and their use in identifying the binding of IRF-5 to nuclear import proteins karyopherin-alpha1 and -beta1. Yonsei Med. J. 2008, 49, 1023-1031. [CrossRef]

11. Yoneda, Y.; Hieda, M.; Nagoshi, E.; Miyamoto, Y. Nucleocytoplasmic protein transport and recycling of Ran. Cell Struct. Funct. 1999, 24, 425-433. [CrossRef] [PubMed]

12. Kimura, M.; Imamoto, N. Biological significance of the importin-beta family-dependent nucleocytoplasmic transport pathways. Traffic 2014, 15, 727-748. [CrossRef] [PubMed]

13. Strom, A.C.; Weis, K. Importin-beta-like nuclear transport receptors. Genome Biol. 2001, 2, REVIEWS3008. [CrossRef] [PubMed]

14. Vetter, I.R.; Arndt, A.; Kutay, U.; Gorlich, D.; Wittinghofer, A. Structural view of the Ran-Importin beta interaction at 2.3 A resolution. Cell 1999, 97, 635-646. [CrossRef]

15. Tamura, K.; Hara-Nishimura, I. Functional insights of nucleocytoplasmic transport in plants. Front. Plant Sci. 2014, 5, 118. [CrossRef]

16. O'Reilly, A.J.; Dacks, J.B.; Field, M.C. Evolution of the karyopherin-beta family of nucleocytoplasmic transport factors; ancient origins and continued specialization. PLOS ONE 2011, 6, e19308.

17. Goldfarb, D.S.; Corbett, A.H.; Mason, D.A.; Harreman, M.T.; Adam, S.A. Importin alpha: A multipurpose nuclear-transport receptor. Trends Cell Biol. 2004, 14, 505-514. [CrossRef]

18. Huang, J.G.; Yang, M.; Liu, P.; Yang, G.D.; Wu, C.A.; Zheng, C.C. Genome-wide profiling of developmental, hormonal or environmental responsiveness of the nucleocytoplasmic transport receptors in Arabidopsis. Gene 2010, 451, 38-44. [CrossRef]

19. Yang, Y.; Wang, W.; Chu, Z.; Zhu, J.-K.; Zhang, H. Roles of Nuclear Pores and Nucleo-cytoplasmic Trafficking in Plant Stress Responses. Front. Plant Sci. 2017, 8, 574. [CrossRef] 
20. Luo, Y.; Wang, Z.; Ji, H.; Fang, H.; Wang, S.; Tian, L.; Li, X. An Arabidopsis homolog of importin beta1 is required for ABA response and drought tolerance. Plant J. 2013, 75, 377-389. [CrossRef]

21. Hunter, C.A.; Aukerman, M.J.; Sun, H.; Fokina, M.; Poethig, R.S. PAUSED encodes the Arabidopsis exportin-t ortholog. Plant Physiol. 2003, 132, 2135-2143. [CrossRef] [PubMed]

22. Li, J.; Chen, X. PAUSED, a putative exportin-t, acts pleiotropically in Arabidopsis development but is dispensable for viability. Plant Physiol. 2003, 132, 1913-1924. [CrossRef] [PubMed]

23. Musarella, C. Solanum torvum Sw. (Solanaceae): A new alien species for Europe. Genet Resour. Crop Evol. 2020, 67, 515-522. [CrossRef]

24. FAOSTAT. Available online: http://www.fao.org/faostat/en/\$delimiter"026E30F\$\#data/QC (accessed on 6 June 2018).

25. Knapp, S.; Vorontsova, M.S.; Särkinen, T. Dichotomous keys to the species of Solanum L. (Solanaceae) in continental Africa, Madagascar (incl. the Indian Ocean islands), Macaronesia and the Cape Verde Islands. PhytoKeys 2019, 127, 39-76. [CrossRef]

26. The Potato Genome Sequencing Consortium. Genome sequence and analysis of the tuber crop potato. Nature 2011, 475, 189-195. [CrossRef]

27. Hawkes, J. The Potato: Evolution, Biodiversity and Tenetic Resources; Belhaven Press: London, UK, 1990.

28. Aversano, R.; Contaldi, F.; Ercolano, M.R.; Grosso, V.; Iorizzo, M.; Tatino, F.; Xumerle, L.; Dal Molin, A.; Avanzato, C.; Ferrarini, A.; et al. The Solanum commersonii Genome Sequence Provides Insights into Adaptation to Stress Conditions and Genome Evolution of Wild Potato Relatives. Plant Cell 2015, 27, 954-968. [CrossRef]

29. Esposito, S.; Aversano, R.; Bradeen, J.M.; Di Matteo, A.; Villano, C.; Carputo, D. Deep-sequencing of Solanum commersonii small RNA libraries reveals riboregulators involved in cold stress response. Plant Biol. (Stuttg) 2020, 22 Suppl. 1, 133-142. [CrossRef]

30. Esposito, S.; Aversano, R.; D’Amelia, V.; Villano, C.; Alioto, D.; Mirouze, M.; Carputo, D. Dicer-like and RNA-dependent RNA polymerase gene family identification and annotation in the cultivated Solanum tuberosum and its wild relative S. commersonii. Planta 2018, 248, 729-743. [CrossRef]

31. Massa, A.N.; Childs, K.L.; Lin, H.; Bryan, G.J.; Giuliano, G.; Buell, C.R. The transcriptome of the reference potato genome Solanum tuberosum Group Phureja clone DM1-3 516R44. PLoS ONE 2011, 6, e26801. [CrossRef]

32. Harel, A.; Forbes, D.J. Importin beta: Conducting a much larger cellular symphony. Mol. Cell 2004, 16, 319-330.

33. Bollman, K.M.; Aukerman, M.J.; Park, M.Y.; Hunter, C.; Berardini, T.Z.; Poethig, R.S. HASTY, the Arabidopsis ortholog of exportin 5/MSN5, regulates phase change and morphogenesis. Development 2003, 130, 1493-1504. [CrossRef] [PubMed]

34. Wang, W.; Ye, R.; Xin, Y.; Fang, X.; Li, C.; Shi, H.; Zhou, X.; Qi, Y. An importin beta protein negatively regulates MicroRNA activity in Arabidopsis. Plant Cell 2011, 23, 3565-3576. [CrossRef] [PubMed]

35. Xu, S.; Zhang, Z.; Jing, B.; Gannon, P.; Ding, J.; Xu, F.; Li, X.; Zhang, Y. Transportin-SR Is Required for Proper Splicing of Resistance Genes and Plant Immunity. PLoS Genet. 2011, 7, e1002159. [CrossRef] [PubMed]

36. Zhang, Z.; Guo, X.; Ge, C.; Ma, Z.; Jiang, M.; Li, T.; Koiwa, H.; Yang, S.W.; Zhang, X. KETCH1 imports HYL1 to nucleus for miRNA biogenesis in Arabidopsis. Proc. Natl. Acad. Sci. USA 2017, 114, 4011-4016. [CrossRef] [PubMed]

37. Zheng, Y.; Zhan, Q.; Shi, T.; Liu, J.; Zhao, K.; Gao, Y. The nuclear transporter SAD2 plays a role in calciumand $\mathrm{H} 2 \mathrm{O} 2$-mediated cell death in Arabidopsis. Plant J. 2020, 101, 324-333. [CrossRef] [PubMed]

38. Verslues, P.E.; Guo, Y.; Dong, C.H.; Ma, W.; Zhu, J.K. Mutation of SAD2, an importin beta-domain protein in Arabidopsis, alters abscisic acid sensitivity. Plant J. 2006, 47, 776-787. [CrossRef]

39. Kroukamp, H.; den Haan, R.; van Wyk, N.; van Zyl, W.H. Overexpression of native PSE1 and SOD1 in Saccharomyces cerevisiae improved heterologous cellulase secretion. Appl. Energy 2013, 102, 150-156. [CrossRef]

40. Makhnevych, T.; Lusk, C.P.; Anderson, A.M.; Aitchison, J.D.; Wozniak, R.W. Cell cycle regulated transport controlled by alterations in the nuclear pore complex. Cell 2003, 115, 813-823. [CrossRef]

41. Ueta, R.; Fukunaka, A.; Yamaguchi-Iwai, Y. Pse1p mediates the nuclear import of the iron-responsive transcription factor Aft1p in Saccharomyces cerevisiae. J. Biol. Chem. 2003, 278, 50120-50127. [CrossRef]

42. Mosammaparast, N.; Jackson, K.R.; Guo, Y.; Brame, C.J.; Shabanowitz, J.; Hunt, D.F.; Pemberton, L.F. Nuclear import of histone H2A and H2B is mediated by a network of karyopherins. J. Cell Biol. 2001, 153, 251-262. [CrossRef] 
43. Thiriet, C.; Hayes, J.J. Histone dynamics during transcription: Exchange of H2A/H2B dimers and H3/H4 tetramers during pol II elongation. Results Probl. Cell. Differ. 2006, 41, 77-90. [PubMed]

44. Yaseen, N.R.; Blobel, G. Cloning and characterization of human karyopherin beta3. Proc. Natl. Acad. Sci. tUSA 1997, 94, 4451-4456. [CrossRef] [PubMed]

45. Hu, B.; Jin, J.; Guo, A.Y.; Zhang, H.; Luo, J.; Gao, G. GSDS 2.0: An upgraded gene feature visualization server. Bioinformatics 2015, 31, 1296-1297. [CrossRef] [PubMed]

46. Thompson, J.D.; Higgins, D.G.; Gibson, T.J. CLUSTAL W: Improving the sensitivity of progressive multiple sequence alignment through sequence weighting, position-specific gap penalties and weight matrix choice. Nucleic Acids Res. 1994, 22, 4673-4680. [CrossRef] [PubMed]

47. Liu, N.; Fromm, M.; Avramova, Z. H3K27me3 and H3K4me3 chromatin environment at super-induced dehydration stress memory genes of Arabidopsis thaliana. Mol. Plant 2014, 7, 502-513. [CrossRef]

48. Song, S.; Hao, L.; Zhao, P.; Xu, Y.; Zhong, N.; Zhang, H.; Liu, N. Genome-wide Identification, Expression Profiling and Evolutionary Analysis of Auxin Response Factor Gene Family in Potato (Solanum tuberosum Group Phureja). Sci Rep. 2019, 9, 1755. [CrossRef]

49. Livak, K.J.; Schmittgen, T.D. Analysis of relative gene expression data using real-time quantitative PCR and

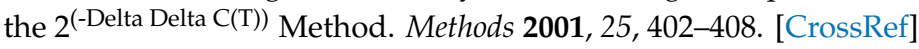

50. Faivre-Rampant, O.; Gilroy, E.M.; Hrubikova, K.; Hein, I.; Millam, S.; Loake, G.J.; Birch, P.; Taylor, M.; Lacomme, C. Potato virus X-induced gene silencing in leaves and tubers of potato. Plant Physiol. 2004, 134, 1308-1316. [CrossRef]

51. Lacomme, C.; Chapman, S. Use of potato virus X (PVX)-based vectors for gene expression and virus-induced gene silencing (VIGS). Curr. Protoc. Microbiol. 2008. [CrossRef]

(C) 2020 by the authors. Licensee MDPI, Basel, Switzerland. This article is an open access article distributed under the terms and conditions of the Creative Commons Attribution (CC BY) license (http://creativecommons.org/licenses/by/4.0/). 